\title{
Electroacupuncture ameliorates experimental colitis induced by TNBS through activation of interleukin-10 and inhibition of iNOS in mice ${ }^{1}$
}

\author{
Annya Costa Araujo de Macedo Goesi, Francisco Maxwell Martins Pinto ${ }^{\text {II }}$, Guilherme Cardoso Fernandes ${ }^{\mathrm{II}}$, Jessica Sales

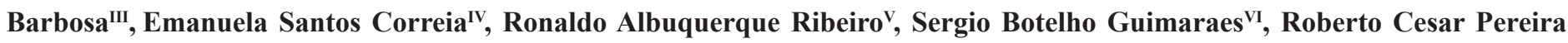 \\ Lima Júnior ${ }^{\mathrm{VII}}$, Gerly Anne de Castro Brito ${ }^{\mathrm{VIII}}$, Lusmar Veras Rodrigues ${ }^{\mathrm{IX}}$
}

DOI: http://dx.doi.org/10.1590/S0102-86502014001900004

IFellow PhD degree, Postgraduate Program in Surgery, Department of Surgery, Federal University of Ceara (UFC), Fortaleza-CE, Brazil. Conception and design of the study, technical procedures, acquisition and interpretation of data.

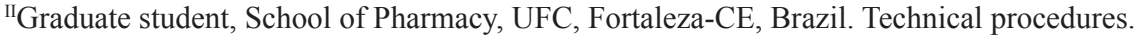

III Graduate student, School of Medicine, UFC, Fortaleza-CE, Brazil. Technical procedures.

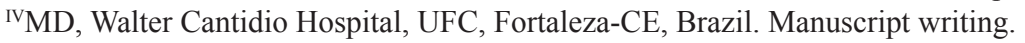

${ }^{v}$ Full Professor, Postgraduate Program in Surgery, Department of Surgery, UFC, Fortaleza-CE, Brazil. Conception and design of the study, interpretation of data.

${ }^{v} \mathrm{PhD}$, Associate Professor, Department of Surgery, Head, Experimental Surgical Research Laboratory (LABCEX), UFC, Fortaleza-CE, Brazil. Conception and design of the study, manuscript writing, critical revision.

${ }^{\mathrm{VII}} \mathrm{PhD}$, Associate Professor, Postgraduate Program in Pharmacology, Department of Pharmacology, UFC, Fortaleza-CE, Brazil. Design of the study, interpretation of data.

${ }^{V I I I} \mathrm{PhD}$, Full Professor, Postgraduate Program in Morphology, Department of Morphology, UFC, Fortaleza-CE, Brazil. Histopathological analysis, acquisition and interpretation of data

${ }^{\mathrm{IX}} \mathrm{PhD}$, Full Professor, Department of Surgery, UFC, Fortaleza-CE, Brazil. Conception, design, intellectual and scientific content of the study; critical revision, final approval of the manuscript.

\footnotetext{
ABSTRACT

PURPOSE: To study the anti-inflammatory actions of electroacupuncture (EAc) on an experimental colitis model in mice.

METHODS: Thirty-eight male Swiss mice, divided in five groups, were subjected to induction of colitis by TNBS in 50\% ethanol. Saline (SAL) and ethanol (ETNL) groups served as controls. TNBS+EAc and TNBS+ dexamethasone subgroups were treated with EAc $100 \mathrm{~Hz}$ and dexamethasone (DEXA) $1 \mathrm{mg} / \mathrm{Kg} /$ day, respectively. After three days, a colon segment was obtained for quantification of myeloperoxidase (MPO) activity, immunohistochemistry for iNOS, malondialdehyde (MDA) and cytokines (IL-1 $\beta$ and IL-10).

RESULTS: Neutrophilic activity, assayed as MPO activity, was significantly higher in the TNBS colitis group than that in the saline control group. TNBS+EAc group showed suppression of IL-10 in the colon. EAc treatment significantly reduced the concentration of MDA and the expression of iNOS, as compared to the other groups. CONCLUSION: Electroacupuncture 100Hz applied to acupoint ST36 promotes an anti-inflammatory action on the TNBS-induced colitis, mediated by increase of IL-10 and decrease of iNOS expression. Key words: Electroacupuncture. Inflammation. Colitis. Mice.
} 


\section{Introduction}

Inflammatory bowel disease (IBD) is an immune-mediated chronic intestinal condition mostly represented by ulcerative colitis and Crohn's disease. Both exogenous factors (e.g. composition of normal intestinal microbiota) and endogenous host factors (intestinal epithelial cell barrier function, innate and adaptive immune function) interact to cause a chronic state of dysregulated mucosal immune function. IBD is currently considered an inappropriate immune response to the commensal microbiota in the intestines, with or without some component of autoimmunity ${ }^{1}$.

The mainstay of therapy for IBD is 5-aminosalicylic acid (5-ASA) agents and glucocorticoids as well as other immunosuppressant drugs. However, the long term use of such agents may give rise to adverse side effects ${ }^{2,3}$ a fungal decapeptide first introduced in 1983, has significantly improved the outcome of renal transplantation, and remains the first line immunosupressant for pediatric recipients. CsA has a narrow therapeutic range because of the fine line between adequate immunosuppression and the risk of drug-induced side effects. Furthermore, considerable inter- and intrapatient variability does exist [Filler et al. 1999]. The pre-dose trough concentration is routinely used for therapeutic drug monitoring [Bunchman et al. 1998]. The most significant side effect is nephrotoxicity, which may present differently at different times after transplantation. Renal vasoconstriction, especially involving the afferent renal arterioles, has been strongly implicated as a primary factor in acute reversible CsA nephrotoxicity. Alpha-adrenergic and calcium channel blockade with either verapamil or nifedipine ameliorates vasospasm and impairment of renal function that accompany CsA toxicity. Because of this vasoconstrictive effect, CsA may increase ischemic graft damage in the early posttransplant period. CsA side effects can be eliminated by reducing the dosage of the drug. We present an unusual case of nephrotoxicity and impaired renal function with a very low CsA blood trough concentration (50 ng/ml. Acupuncture has long been used for the treatment of many diseases. Recent studies have demonstrated that acupuncture has immunoregulatory effects as it may modulate the expression of many cytokines ${ }^{4}$. Electroacupuncture (EAc) has been reported to activate hypothalamic-pituitary-adrenal axis releasing glucocorticoids that have important anti-inflammatory properties $^{5,6}$. EAc is also reported to modulate the secretion of cathecolamines from adrenal medulla by influencing sympathetic activity $^{7}$. Cathecolamines are known to induce anti-inflammatory responses through activation of $\beta$-adrenergic receptors ${ }^{8}$. However, the therapeutic mechanism of acupuncture on IBD is uncertain.
In this study, we induced inflammatory colitis in mice and stimulated them with EAc aiming to assess the effect of EAc in IBD. We investigated whether the EAc treatment would reduce the tissue inflammatory response through myeloperoxidase activity (MPO), as well as immunohistochemistry for iNOS, malondialdehyde (MDA), IL-1 $\beta$, IL-10 on colic tissue.

\section{Methods}

\section{Animal preparation and experimental groups}

Approval for experimental use of laboratory animals was obtained from the local Ethics Committee on Animal Use (CEPA), protocol \#11/2012. All surgical procedures and animal handling were conducted in accordance with the Brazilian Federal Law No. 11794 of October 8, 2008 (http://www.planalto.gov.br/ccivil_03/ Ato2007-2010/2008/Lei/L11794.htm).

Thirty-eight male Swiss mice average weight $30 \mathrm{~g}$ were used in the experiments. Mice were housed in stainless steel cages and maintained under a $12 \mathrm{~h}$ light/dark cycle with a room temperature of $26 \pm 2^{\circ} \mathrm{C}$. Rats, Mice and Hamsters Chow $\left(\right.$ Labina $\left.^{\circledR}\right)$ - Ralston Purina do Brasil LTDA. - Paulínia - SP) and water were available ad libitum.

\section{Study groups}

Experimental animals were randomized in five groups (6-9 rats for each group): saline control group $(n=8)$, ethanol group $(n=7)$, TNBS group (n=9), TNBS + EAc (n=6) $-100 \mathrm{~Hz}, 1 \mathrm{~h}$ before and $24 \mathrm{~h}$ and $48 \mathrm{~h}$ after colitis induction, TNBS + dexamethasone ( $\mathrm{n}=8)-1 \mathrm{mg} /$ $\mathrm{Kg}$ subcutaneously $1 \mathrm{~h}$ before and $24 \mathrm{~h}$ and $48 \mathrm{~h}$ after colitis induction.

\section{Induction of experimental colitis}

All experimental animals were fasted for $12 \mathrm{~h}$ before the induction of colitis. Each mouse was lightly anesthetized with inhaled isoflurane $2 \%$ and a polyethylene cannula (4Fr) was inserted into the lumen of the colon via the anus. The tip of the cannula was positioned at $4 \mathrm{~cm}$ proximal to the anus for the infusion of $80 \mu \mathrm{L}$ saline, $50 \%$ ethanol or TNBS solution dissolved in a $50 \%$ ethanol $(2 \mathrm{mg} / 80 \mu \mathrm{L})$, as appropriate 9

\section{EAc treatment}

Anesthetized mice were stimulated at ST-36 (bilateral) acupoint. ST-36 (Zusanli) lies just below fibular head of the mouse's hind $\operatorname{leg}^{10}$ the specificity of the point and the reproducibility 
of the location of the point are prerequisite to the specificity and reproducibility of research involving acupuncture stimulation. The transpositional method, which locates animal acupoints (AAs. Acupuncture needles $(0.18 \mathrm{~mm}$ diameter, $8 \mathrm{~mm}$ length) were connected to a flexible electrical wire. Square wave pulses $(100 \mathrm{~Hz}$ frequency, $1 \mathrm{~mA}$ intensity, 1s) were applied to the needles for 20 minutes, using an electric stimulator (Sikuro DS-100, Sao Paulo, Brazil) $1 \mathrm{~h}$ before and $24 \mathrm{~h}$ and $48 \mathrm{~h}$ after the induction of experimental colitis.

\section{Myeloperoxidase (MPO) assay}

The extent of neutrophil accumulation in the colon was measured by assaying myeloperoxidase (MPO) activity as previously described. In brief, the animals were killed three days after colitis induction, and intestine tissue was harvested and homogenized in two volumes of ice-cold buffer $(0.1 \mathrm{M} \mathrm{NaCl}$, 20mM NaPO4, 12mM Na EDTA), $\mathrm{pH} 4.7$, and centrifuged at $3000 \mathrm{rpm}$ for $15 \mathrm{~min}$. The pellet was then subjected to hypotonic lysis $(0.2 \% \mathrm{NaCl}$ solution, followed 30 secs later by the addition of an equal volume of a solution containing $1.6 \% \mathrm{NaCl}$ ). After a further centrifugation step, the pellet was resuspended in $200 \mu \mathrm{L}$ of $50 \mathrm{mM}$ NaPO4 buffer, $\mathrm{pH} 5.4$, containing $0.5 \%$ hexadecyltrimethylammonium bromide (H-TAB, Sigma). MPO activity in the resuspended pellet was assayed by measuring the change in absorbance at $450 \mathrm{~nm}$ with use of tetramethylbenzidine $(1.6 \mathrm{mM})$ and $\mathrm{H}_{2} \mathrm{O}_{2}(0.5 \mathrm{mM})$. The results were reported as the total number of neutrophils per milligram of tissue by comparing the absorbance of the tissue supernatant with a standard curve of mouse peritoneal neutrophils processed in the same way ${ }^{11}$.

\section{Determination of the $I L-1$ and $I L-10$}

The animals had a sample of their intestine removed on day 3 for analysis of cytokines. The specimen was stored at $-70^{\circ} \mathrm{C}$ until required for assay. The tissue collected was homogenized and processed as described ${ }^{12}$. The detection of IL-10 and IL$1 \beta$ concentrations was determined by ELISA, as described previously. Briefly, microtiter plates were coated overnight at $4{ }^{\circ} \mathrm{C}$ with antibody against mice IL-10 and IL- $1 \beta(2 \mu \mathrm{g} / \mathrm{ml})$. After blocking the plates, the samples and standard at various dilutions were added in duplicate and incubated at $4{ }^{\circ} \mathrm{C}$ for $24 \mathrm{~h}$. The plates were washed three times with buffer. After washing the plates, biotinylated sheep polyclonal anti-IL-10 or anti-IL-1 $\beta$ (diluted 1:1000 with assay buffer $1 \%$ BSA), was added to the wells. After further incubation at room temperature for $1 \mathrm{~h}$, the plates were washed and 50 $\mu$ l of avidin-HRP diluted 1:5000 were added. The color reagent $o$-phenylenediamine (OPD; $50 \mu \mathrm{l}$ ) was added $15 \mathrm{~min}$ later and the plates were incubated in the dark at $37^{\circ} \mathrm{C}$ for $15-20$ min. The enzyme reaction was stopped with $\mathrm{H}_{2} \mathrm{SO}_{4}$ and absorbance was measured at $490 \mathrm{~nm}$. Values were expresses as picograms/ milliliter $(\mathrm{pg} / \mathrm{ml})^{12}$.

\section{Immunohistochemistry for iNOS}

Colonic tissues were fixed in $4 \%$ formalin in $0.1 \mathrm{M}$ phosphate buffer, dehydrated with increasing concentrations of ethanol, embedded in paraffin, and sectioned. Sections ( $5 \mu \mathrm{m}$ thick) were mounted on slides, cleared and hydrated. After inhibition of endogenous peroxidases, tissues were treated with a buffered blocking solution (10\% BSA in PBS) for $15 \mathrm{~min}$. The sections were then incubated with primary antibody (anti-iNOS, 1/50 in PBSTween $20, \mathrm{v} / \mathrm{v}$ ) or control solutions at $37^{\circ} \mathrm{C}$ for $45 \mathrm{~min}$. Controls included buffer alone or non-specific purified rabbit IgG. Samples were washed with PBS-Tween 20 and incubated with secondary antibody (goat anti-rabbit IgG, peroxidase-conjugated, 1/ 250 in PBS-Tween $20, \mathrm{v} / \mathrm{v}$ ) at $37^{\circ} \mathrm{C}$ for $30 \mathrm{~min}$. Thereafter the sections were washed as before and incubated with diaminobenzidine solution in the dark at room temperature for $10 \mathrm{~min}$. After washing with water, samples were mounted with Dako 1 far amount aqueous mounting medium (Dako Corporation) and observed with a Leica DFC-295 microscope ${ }^{13}$.

\section{Malondialdehyde (MDA) assay}

MDA levels in the colon were determined as an indicator of lipid peroxidation. The tissue was homogenized in $1.15 \% \mathrm{KCl}$ solution. A measure of $0.1 \mathrm{ml}$ of the homogenate was then added to a reaction mixture containing $0.2 \mathrm{ml}$ of $8.1 \%$ sodium dodecyl sulfate, $1.5 \mathrm{ml}$ of $20 \%$ acetic acid, $1.5 \mathrm{ml}$ of $0.8 \%$ thiobarbituric acid and $0.7 \mathrm{ml}$ of distilled water. Samples were boiled for $1 \mathrm{~h}$ at $95^{\circ} \mathrm{C}$ and centrifuged at $3000 \mathrm{~g}$ for $10 \mathrm{~min}$. The absorbance of the supernatant was measured by spectrophotometry at $650 \mathrm{~nm}^{14}$.

\section{Statistical methods}

Parametric data were expressed as means \pm S.E.M or median (min-max) and were statistically tested by ANOVA followed by Turkey or Student's t-test. Non-parametric data were expressed as median and statistically tested by Kruskall-Wallis followed by Dunn test. The value of $p<0.05$ was considered statistically significant. The GraphPad Prism 6.01 software was used for these analyses. 


\section{Results}

MPO activity

Neutrophilic activity, measured by MPO activity, was significantly higher in the TNBS colitis group than that in the saline control group $(3337 \pm 1335$ neutrophil/mg vs. $997.3 \pm 344.5$ neutrophil/mg, $\mathrm{p}<0.0001)$. But there was no statistical difference in neutrophilic activity between the TNBS group and the TNBS + EA group (3337 \pm 1335 neutrophil/mg vs. $2615 \pm 1355$ neutrophil/ $\mathrm{mg}, \mathrm{p}=0.5064)$. Neutrophilic activity was significantly lower in the TNBS + desamethasone group than in the TNBS group (1342 \pm 469.4 neutrophil/mg vs. $3337 \pm 1335$ neutrophil/mg, $\mathrm{p}=0.0002$ ) (Figure 1).

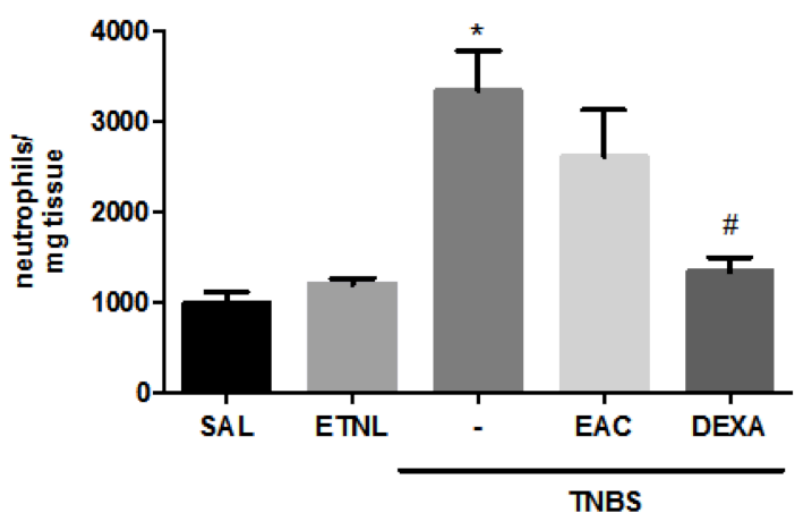

FIGURE 1 - Activity of MPO in the colon on the third day after induction of colitis by TNBS. Bars represent (from left to right) Group SAL, rats treated with saline $(80 \mu 1$, rectal); group ETNL, rats treated with $50 \%$ ethanol $(80 \mu \mathrm{l}$, rectal).; group TNBS, rats induced with TNBS in $50 \%$ ethanol $(2 \mathrm{mg} / 80 \mu \mathrm{L}$, rectal $)$; TNBS+EAc, rats induced with TNBS and treated with EAc $100 \mathrm{~Hz}$ (1mA applied to ST-36 acupoint bilaterally for 20 minutes); TNBS+DEXA, rats induced with TNBS and treated with dexamethasone. (1mg/kg SC) every 24 hours for three days TNBS group showed an increase in the neutrophil infiltration into the colon compared to SAL group (* $\mathrm{p}<0.05)$. DEXA group showed statistical difference compared to the TNBS group. Data are expressed as mean \pm S.E.M., $* \mathrm{p}<0.05$ vs. saline; \# $\mathrm{p}<0.05$ vs TNBS (ANOVA / Tukey test).

\section{Effects of EAc on the IL-1 $\beta$ content}

When compared to the saline control group, the IL-1 $\beta$ content in the colonic tissue of the TNBS group was significantly higher (297.7 $\pm 203.4 \mathrm{pg} / \mathrm{mL}$ vs. $892.8 \pm 436.3 \mathrm{pg} / \mathrm{mL}, \mathrm{p}=0.0377$ ). However, there was no statistical difference in the IL-1 $\beta$ content between TNBS and TNBS + EA groups $(892.8 \pm 436.3 \mathrm{pg} / \mathrm{mL}$ vs. $568.9 \pm 504.5 \mathrm{pg} / \mathrm{mL}$, $\mathrm{p}=0.5475$ ). There was statistical difference in IL-1 $\beta$ content between the TNBS + dexamethasone group and TNBS group $(892.8 \pm 436.3 \mathrm{pg} /$ $\mathrm{mL}$ vs. $400.2 \pm 126.5 \mathrm{pg} / \mathrm{mL}, \mathrm{p}=0.0302$ ) (Figure 2 ).

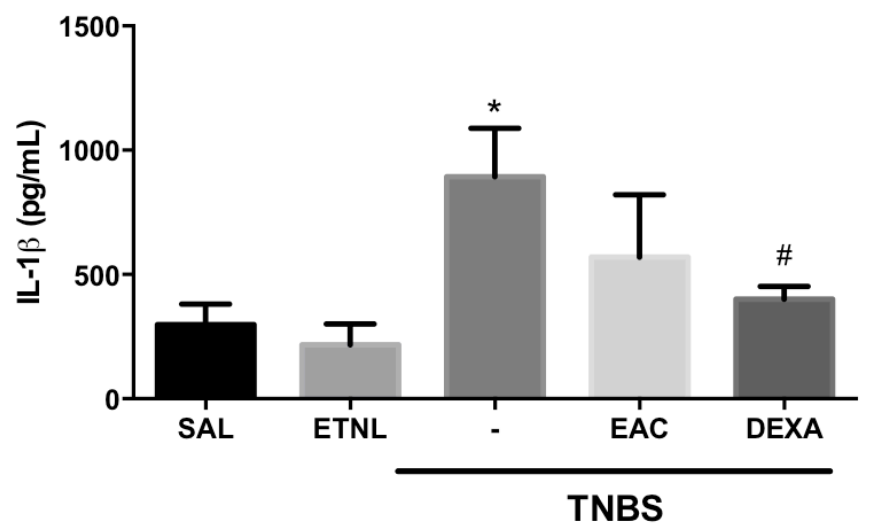

FIGURE 2 - Tissue (colon) concentration of IL-1 $\beta$ on the third day after the induction of colitis by TNBS. Bars represent (from left to right) Group SAL, rats treated with saline ( $80 \mu 1$, rectal); group ETNL, rats treated with $50 \%$ ethanol $(80 \mu \mathrm{l}$, rectal); group TNBS, rats induced with TNBS in $50 \%$ ethanol $(2 \mathrm{mg} / 80 \mu \mathrm{L}$, rectal); TNBS+EAc, rats induced with TNBS and treated with EAc $100 \mathrm{~Hz}$ (1mA applied to ST-36 acupoint bilaterally for 20 minutes); TNBS+DEXA, rats induced with TNBS and treated with dexamethasone. (1mg/kg SC) every 24 hours for three days. IL- $1 \beta$ concentration increased, on the third day in TNBS group (\# $\mathrm{p}<0.05$ ) This effect was prevented by DEXA. Data are expressed as mean \pm S.E.M., ${ }^{*} \mathrm{p}<0.05$ vs. saline; \# $\mathrm{p}<0.05$ vs TNBS (ANOVA / Tukey test).

\section{Effects of EAc on the IL-10 content}

As shown in the Figure 3, IL-10 content in the colonic tissue was significantly suppressed in the TNBS group as compared to the

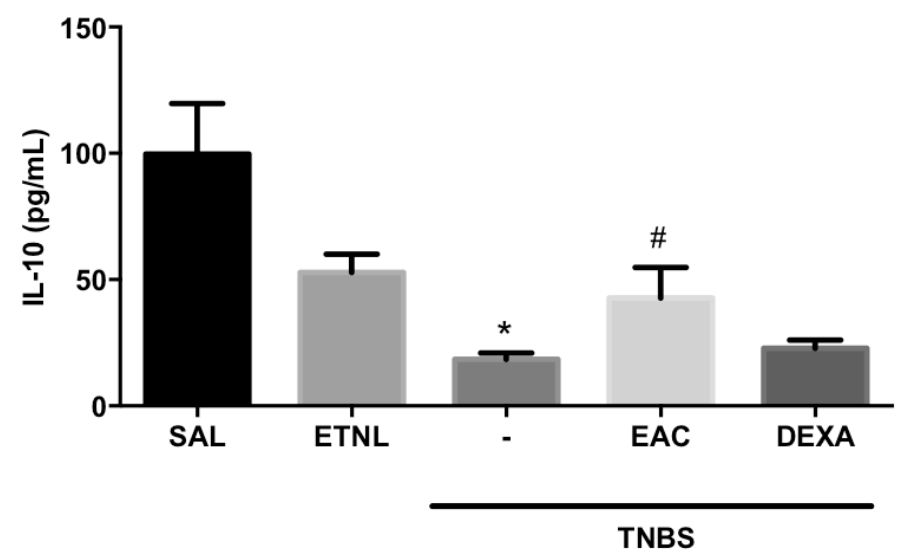

FIGURE 3 - Tissue (colon) concentration of IL-10 on the third day after the induction of colitis by TNBS. Bars represent (from left to right) Group SAL, rats treated with saline ( $80 \mu 1$, rectal); group ETNL, rats treated with $50 \%$ ethanol $(80 \mu \mathrm{l}$, rectal); group TNBS, rats induced with TNBS in $50 \%$ ethanol $(2 \mathrm{mg} / 80 \mu \mathrm{L}$, rectal); TNBS+EAc, rats induced with TNBS and treated with EAc $100 \mathrm{~Hz}$ (1mA applied to ST-36 acupoint bilaterally for 20 minutes); TNBS+DEXA, rats induced with TNBS and treated with dexamethasone. (1mg/kg SC) every 24 hours for three days. The concentration of IL-10 decreased significantly on the third day in TNBS group $(\# p<0.05)$ This effect was reversed by EAc but not by DEXA. Data are expressed as mean \pm S.E.M. ${ }^{*} \mathrm{p}<0.05$ vs. saline; $\# \mathrm{p}<0.05$ vs TNBS (ANOVA/ Tukey test). 
control saline group $(18.42 \pm 5.608 \mathrm{pg} / \mathrm{mL}$ vs. $99.74 \pm 48.98 \mathrm{pg} / \mathrm{mL}$, $\mathrm{p}=0.0007)$. And, when compared to the TNBS group, IL-10 content was significantly higher in the TNBS + EA group $(18.42 \pm 5.608 \mathrm{pg} /$ $\mathrm{mL}$ vs. $42.68 \pm 21.01 \mathrm{pg} / \mathrm{mL}, \mathrm{p}=0.0214)$. There was statistical difference in the IL-10 content between the saline control group and the TNBS + dexamethasone group $(99.74 \pm 48.98 \mathrm{pg} / \mathrm{mL}$ vs. $22.84 \pm$ $7.962 \mathrm{pg} / \mathrm{mL}, \mathrm{p}=0.0008$ ).

\section{Immunohistochemistry for iNOS}

The expression of iNOS in the epithelium $(p=0.0010)$ and in the connective $(\mathrm{p}=0.0053)$ was increased on TNBS group when compared to control saline group. When compared to TNBS group, expression of iNOS in the connective was decreased in the TNBS + EA group $(p=0.0472)$. There was statistical difference in expression of iNOS between the TNBS + dexamethasone group and TNBS group in both the epithelium and connective $(\mathrm{p}=0.0053)$ $(\mathrm{p}=0.0010)$ (Figure 4 and Table 1$)$.

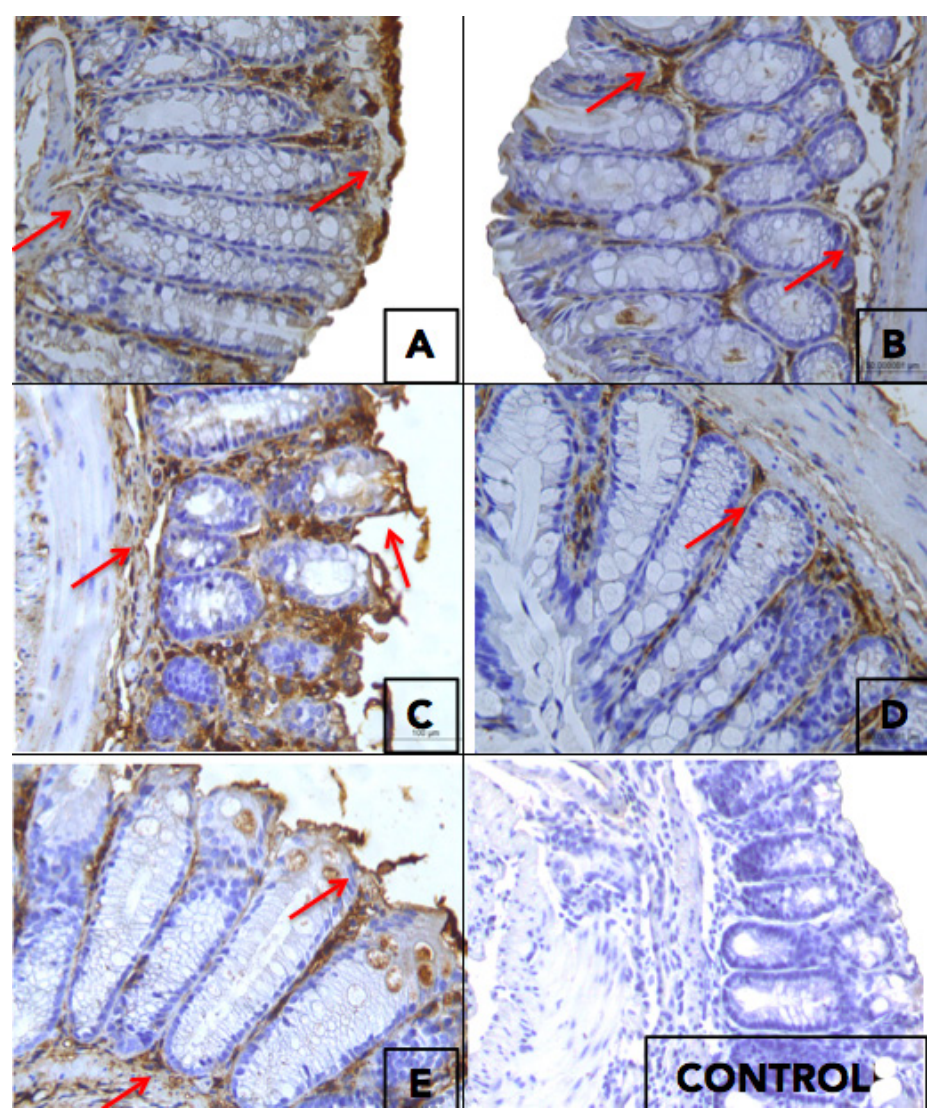

FIGURE 4 - Expression of iNOS. (x200) (A) SAL and (B) ETNL group: photomicrograph of colon showing expression of iNOS in the epithelium and conjunctive tissue (red arrows); (C) TNBS group: expression of iNOS in the epithelium $(++)$ and conjunctive tissue $(++)$; (D) EAC group: iNOS expression in the conjunctive $(+)$; (E) DEXA group: expression of iNOS in the epithelium $(+)$ and conjunctive $(+)$. The symbols $(+)$ and $(++)$ denote the levels of iNOS expression.
TABLE 1 - Immunoexpression of iNOS in the colon tissue on the third day after the induction of colitis by TNBS.

\begin{tabular}{ccc}
\hline \multirow{2}{*}{ Groups } & \multicolumn{2}{c}{ iNOS Immunohistochemical scores } \\
\cline { 2 - 3 } & $\begin{array}{c}\text { Epithelium } \\
(\mathbf{0}-3)\end{array}$ & $\begin{array}{c}\text { Conective tissue } \\
(\mathbf{0}-\mathbf{3})\end{array}$ \\
\hline SAL & $0(0-0)$ & $1(1-1)$ \\
$\mathbf{( N = 8 )}$ & & \\
ETNL & $0(0-1)$ & $2(2-3)$ \\
$\mathbf{( N = 7 )}$ & $\#$ & $*$ \\
TNBS & $3(1-3)$ & $3(3-3)$ \\
$\mathbf{( N = 9 )}$ & $*$ & $*$ \\
TNBS + EAC & $2(1-2)$ & $1(1-2)$ \\
$\mathbf{( N = 6 )}$ & $*$ & $\#$ \\
TNBS + DEXA & $0(0-0)$ & $1(1-1)$ \\
$(\mathbf{N}=\mathbf{8})$ & $\#$ & $\#$ \\
\hline
\end{tabular}

Colitis induced by TNBS in $50 \%$ ethanol $(2 \mathrm{mg} / 80 \mu \mathrm{L}$, rectal). Animals treated with electroacupuncture (EAC) $(100 \mathrm{~Hz}, 1 \mathrm{~mA}$, ST-36 acupoint bilaterally for 20 minutes) or dexamethasone (DEXA) $(1 \mathrm{mg} / \mathrm{kg} \mathrm{SC})$ every 24 hours for three days. Groups treated with saline (SAL) $(0.8 \mu 1$, rectal) and 50\% ethanol (ETNL) $(0.8 \mu$, rectal) served as controls. TNBS group showed higher expression of iNOS in the epithelium and connective after the third day. EAc prevented iNOS expression in the connective tissue, while DEXA. prevented iNOS expression in the epithelium and connective tissue. Data are expressed as median (min-max) * $\mathrm{p}<0.05$ vs. saline; $\# \mathrm{p}<0.05$ vs TNBS (Kruskal-Wallis/ Dunn Test).

\section{MDA assay}

MDA concentration was increased on TNBS group when compared to control saline group $(1501 \pm 753.8 \mathrm{pg} / \mathrm{mL}$ vs. $552 \pm$ $198.2 \mathrm{pg} / \mathrm{mL}, \mathrm{p}=0.0446)$. When compared to TNBS group, MDA concentration was decreased in the TNBS + EA group (1501 \pm $753.8 \mathrm{pg} / \mathrm{mL}$ vs. $497.2 \pm 378.3 \mathrm{pg} / \mathrm{mL}, \mathrm{p}=0.0104)$. There was statistical difference in MDA concentration between the TNBS + dexamethasone group and TNBS group in both the epithelium and connective (239.8 \pm $51.49 \mathrm{pg} / \mathrm{mL}$ vs. $1501 \pm 753.8 \mathrm{pg} / \mathrm{mL}, \mathrm{p}=0.0010$ ) (Figure 5).

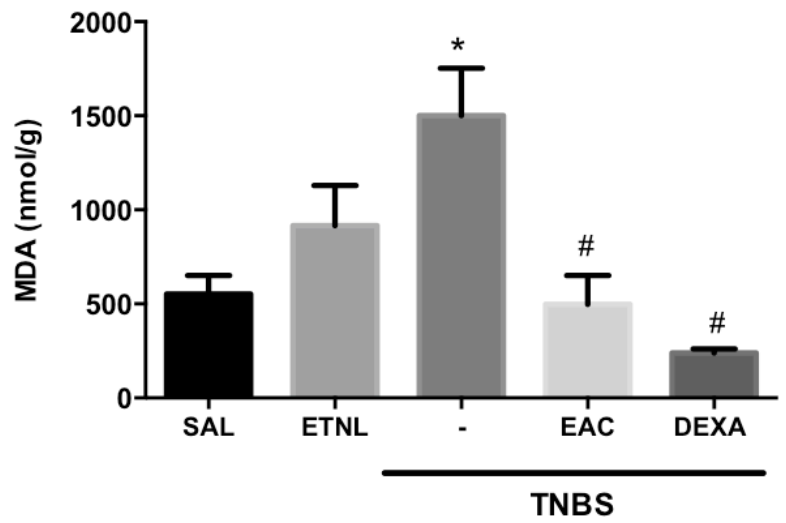

FIGURE 5 - Tissue (colon) concentration of MDA on the third day after the induction of colitis by TNBS. Bars represent (from left to

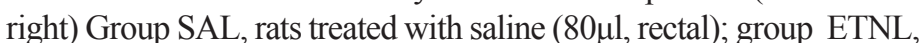
rats treated with $50 \%$ ethanol $(80 \mu 1$, rectal).; group TNBS, rats induced with TNBS in $50 \%$ ethanol $(2 \mathrm{mg} / 80 \mu \mathrm{L}$, rectal $)$; TNBS+EAc, rats induced with TNBS and treated with EAc $100 \mathrm{~Hz}$ (1mA applied to ST36 acupoint bilaterally for 20 minutes); TNBS+DEXA, rats induced with TNBS and treated with dexamethasone. ( $1 \mathrm{mg} / \mathrm{kg} \mathrm{SC})$ every 24 hours for three days. MDA concentration increased significantly on the third day in TNBS group compared with SAL control $(* p<0.05)$ This effect was by EAc and DEXA. Data are expressed as mean \pm S.E.M. * $\mathrm{p}<0.05$ vs. saline; $\# \mathrm{p}<0.05$ vs TNBS (ANOVA / Tukey test). 


\section{Discussion}

Experimental colitis animal models have been developed to study the mechanisms of IBD, and are also tools for pre-clinical evaluation of new treatments efficacy. They exhibit some, but not all, phonotypical and pathophysiological characteristics of human IBD. According to Morris ${ }^{9}$, the animal model utilized in this study is one of easy induction, low cost, reasonable reproducibility, and can be employed with mice, rats and rabbits. In this model, ethanol breaks epithelial integrity, allowing penetration of TNBS and development of colitis resembling IBD 9 .

In this study, the MPO activity was increased in intestine segments ETNL and TNBS groups, after the third day of colitis induction. MPO is an enzyme found in neutrophils that has been used as a quantitative index of inflammation in several tissues, including the intestine, and reflects the influx of PMN to the area of interest. These results confirm induction of colitis and are in accordance with the findings of Appleyard and Wallace on TNBS induced colitis in rats ${ }^{15}$.

The choice of acupuncture treatment was based on the fact that it activates defense systems, proliferation and cellular influx. It also regulates the cells involved in the release of mediators: substance $\mathrm{P}$, bradykinin, calcitonin, vasoactive intestinal polypeptide, neurokinin $\mathrm{A}$, neuropeptide $\mathrm{Y}, \beta$-endorphin, cytokines IL-1 $\beta$, Il-2, IL-4, IL-6, IL-10, IFN- $\gamma$, TNF- $\alpha$, nitric oxide, eicosanoid, and other vasoactive substances ${ }^{16}$.

The acupoint ST=36 used in the present study is the most used acupoint for immune regulation purposes, including gastrointestinal autoimmune diseases, albeit the mechanisms have yet to be understood ${ }^{17}$.

It is well known that anti-inflammatory cytokines are synthesized mainly by T-reg lymphocytes and have immune regulatory activity over lymphocytes and macrophages. They inhibit the release of inflammatory mediators, exerting a strong anti-inflammatory action and modulating both expression and activity of iNOS and thus regulating production of $\mathrm{NO}^{18}$. In our study, there was an elevation of IL-10 in animals treated with EAc, a cytokine of Th2 profile associated with anti-inflammatory response. That could, at least partially, explain the protective effect. Conversely, increased levels of IL-1 $\beta$ observed in animals with TNBS induced colitis were not affected by EAc applied to ST-36 acupoint.

Similar findings have been described. Yan et al. ${ }^{18}$ demonstrated that application of EAc to ST-37 (Shangjuxu) acupoint had therapeutic effects on TNBS induced colitis, through modulation of tissue lesion, specifically decreasing concentration of pro-inflammatory cytokines (IL-1) and increasing concentration of anti-inflammatory cytokines (IL-4).

This investigation has shown that EAc significantly decreased expression of iNOS on connective tissue of the colonic wall. At this point, it was postulated that perhaps nitric oxide, generating nitrogen and oxygen reactive intermediates, was not one of the final mediators of the inflammatory lesion observed on colitis.

The induction of iNOS on inflamed human colon epithelium is associated with formation of nitrogen species (RNS) and cellular nitration. What's more, nitrogen and RNS play a key role on IBD. Those species are cytotoxic agents, inducing lipid peroxidation and cellular oxidative stress, leading to cellular disfunction, damage and eventually death ${ }^{19}$.

Zingarelli et al. ${ }^{19}$ reasoned that the increase in $\mathrm{NO}$ production catalysed by iNOS seems to be the cause for lesions on the colonic tissue in several experimental colitis models. In patients with UC, whose iNOS activity is elevated, there is an increase on the concentration of nitrite detected by rectal washing and in biopsy samples.iNOS expression and activity, tyrosine nitration and malondialdehyde formation (as indexes of nitrosative and oxidative stress

This study also demonstrated a marked increase on intestinal levels of MDA in animals with TNBS-induced colitis. MDA had its levels significantly diminished as consequence of treatment with EAc applied to ST-36 acupoint. Since the treatment with EAc promoted an elevation of IL-10 levels, suppressed the expression of iNOS and diminished the concentration of MDA in the intestinal segments, it is reasonable to assume that the antiinflammatory action of EAc is due, partially, to anti-oxidative properties.

The results of this study have shown that EAc applied bilaterally to ST-36 acupoints with frequency of $100 \mathrm{~Hz}$ and intensity of $1 \mathrm{~mA}$, for 20 minutes, during three days attenuates TNBS-induced colitis in Swiss mice. These effects were followed by modulation of oxidative and inflammatory stress parameters.

\section{Conclusion}

Electroacupuncture $100 \mathrm{~Hz}$ applied to acupoint ST-36 promotes an anti-inflammatory action on TNBS-induced colitis, mediated by increase of IL-10 and decrease of iNOS expression.

\section{References}

1. Kaser A, Zeissig S, Blumberg RS. Inflammatory bowel disease. Annu Rev Immunol. 2010;28:573-621. doi: 10.1146/annurevimmunol-030409-101225. 
2. Di Paolo MC, Paoluzi OA, Pica R, Iacopini F, Crispino P, Rivera M, Spera G, Paoluzi P. Sulphasalazine and 5-aminosalicylic acid in long-term treatment of ulcerative colitis: report on tolerance and side-effects. Dig Liver Dis. 2001 Oct;33(7):563-9. PMID: 11816545 .

3. Jankauskiene A, Druskis V, Laurinavicius A. Cyclosporine nephrotoxicity: associated allograft dysfunction at low trough concentration. Clin Nephrol. 2001 Dec;56(6):S27-9. PMID: 11770808.

4. Tian L, Huang YX, Tian M, Gao W, Chang Q. Down regulation of electroacupuncture at ST36 on TNF-alpha in rats with ulcerative colitis. World J Gastroenterol. 2003 May;9(5):1028-33. PMID: 12717850 .

5. Liao YY, Seto K, Saito H, Fujita M, Kawakami M. Effect of acupuncture on adrenocortical hormone production: I. Variation in the ability for adrenocortical hormone production in relation to the duration of acupuncture stimulation. Am J Chin Med. 1979;7(4):36271. PMID: 232372.

6. Liao YY, Seto K, Saitoh H, Kawakami M. Effect of acupuncture on adrenocortical hormone production in rabbits with a central lesion. Am J Chin Med. 1981;9(1):61-73. PMID: 7304500.

7. Mori H, Uchida S, Ohsawa H, Noguchi E, Kimura T, Nishijo K. Electro-acupuncture stimulation to a hindpaw and a hind leg produces different reflex responses in sympathoadrenal medullary function in anesthetized rats. J Auton Nerv Syst. 2000 Mar 15;79(23):93-8. PMID: 10699639.

8. Woiciechowsky C, Schöning B, Lanksch WR, Volk HD, Döcke WD. Mechanisms of brain-mediated systemic anti-inflammatory syndrome causing immunodepression. J Mol Med (Berl). 1999 Nov;77(11):769-80. PMID: 10619437.

9. Morris GP, Beck PL, Herridge MS, Depew WT, Szewczuk MR, Wallace JL. Hapten-induced model of chronic inflammation and ulceration in the rat colon. Gastroenterology. 1989 Mar;96(3):795803. PMID: 2914642.

10. Yin CS, Jeong HS, Park HJ, Baik Y, Yoon MH, Choi CB, Koh HG. A proposed transpositional acupoint system in a mouse and rat model. Res Vet Sci. 2008 Apr;84(2):159-65. PMID: 17559895.

11. Alves-Filho JC, de Freitas A, Russo M, Cunha FQ. Toll-like receptor 4 signaling leads to neutrophil migration impairment in polymicrobial sepsis. Crit Care Med. 2006 Feb;34(2):461-70. PMID: 16424729.

12. Safieh-Garabedian B, Poole S, Allchorne A, Winter J, Woolf CJ. Contribution of interleukin-1 beta to the inflammation-induced increase in nerve growth factor levels and inflammatory hyperalgesia. Br J Pharmacol. 1995 Aug;115(7):1265-75. PMID: 7582555.

13. Hsu SM, Raine L. Protein A, avidin, and biotin in immunohistochemistry. J Histochem Cytochem. 1981 Nov;29(11):1349-53. PMID: 6172466.

14. Mihara M, Uchiyama M. Determination of malonaldehyde precursor in tissues by thiobarbituric acid test. Anal Biochem. 1978 May;86(1):271-8. PMID: 655387.
15. Appleyard CB, Wallace JL. Reactivation of hapten-induced colitis and its prevention by anti-inflammatory drugs. Am J Physiol. 1995 Jul;269(1 Pt 1):G119-25. PMID: 7631788.

16. Zijlstra FJ, van den Berg-de Lange I, Huygen FJ, Klein J. Antiinflammatory actions of acupuncture. Mediators Inflamm. 2003 Apr;12(2):59-69. doi: 10.1080/0962935031000114943.

17. Maeda T, Taniguchi M, Matsuzaki S, Shingaki K, Kanazawa S, Miyata S. Anti-inflammatory effect of electroacupuncture in the $\mathrm{C} 3 \mathrm{H} / \mathrm{HeJ}$ mouse model of alopecia areata. Acupunct Med. 2013 Mar;31(1):117-9. doi: 10.1136/acupmed-2012-010240. 18. Yan J, Zhang H, Chen CT, Yang QY, Liao WF, Chen PG. Effects of electroacupuncture at Shangjuxu (ST 37) on interleukin-1beta and interleukin-4 in the ulcerative colitis model rats.J Tradit Chin Med. 2009 Mar;29(1):60-3. PMID: 19514191.

19. Zingarelli B, Szabó C, Salzman AL. Reduced oxidative and nitrosative damage in murine experimental colitis in the absence of inducible nitric oxide synthase. Gut. 1999 Aug;45(2):199-209. PMID: 10403731.

\section{Correspondence:}

Prof. Dr. Lusmar Veras Rodrigues

Avenida Abolição, 4043/2401 Bloco J

60165-082 Fortaleza - CE Brasil

Tel.: (55 85)3366-8063

mcirur@ufc.br

lusmarveras@terra.com.br

Received: Aug 12, 2014

Review: Oct 10, 2014

Accepted: Nov 11, 2014

Conflict of interest: none

Financial sources: National Council for Scientific and Technological Development $(\mathrm{CNPq})$ and Ceara Foundation for Scientific and Technological Development (FUNCAP)

${ }^{1}$ Research performed at Laboratory of Pharmacology of Inflammation and Cancer (LAFICA), Department of Physiology and Pharmacology, Federal University of Ceara (UFC), Fortaleza-CE, Brazil. Part of Master degree thesis, Postgraduate Program in Surgery, UFC. Tutor: Prof. Dr. Lusmar Veras Rodrigues. 